\title{
B7H6: A Bio-Marker for the Development of Cancer-Targeted Immunotherapy Applications
}

\author{
Mariana Phillips ${ }^{1}$, Constantine Bitsaktsis ${ }^{2}$, and David Sabatino ${ }^{1}$ \\ ${ }^{1}$ Department of Chemistry and Biochemistry; ${ }^{2}$ Department of Biological Sciences, Seton Hall University, \\ 400 South Orange Ave, South Orange, NJ, 07079, USA
}

\section{Introduction}

Natural Killer (NK) cells are a class of cytotoxic lymphocytes with the ability to rapidly eliminate transformed or infected cells upon activation [1]. A key mediator of the NK cell line activity, NKp30, is a member of the natural cytotoxicity receptors (NCRs) that signal pro-inflammatory cytokine and chemokine production, as well as the release of cytotoxic agents that leads to tumor cell death [2]. The active search of NKp30-dependent immunostimulatory ligands led to chemical cross-linking studies followed by tryptic digestion, tandem mass spectrometry and proteomic analyses of the leukemia cell line K562 with soluble NKp30-Fc fusion protein which revealed B7H6 as a cell membrane expressed protein ligand of the NKp30 receptor [3]. Mechanistic studies demonstrated that upon binding of B7H6 to NKp30, the association of a transmembrane arginine residue of NKp30 to an ITAM bearing protein, such as $\mathrm{CD} 3 \zeta$, initiated a signaling cascade that resulted in the reorganization of the NK cells' cytoskeleton and initiation of $\mathrm{Ca}^{2+}$ flux that ultimately led to the secretion of inflammatory cytokines [4]. Consequently, the discovery of the B7H6-NKp30 binding interaction offers a new opportunity in the development of tumor immunotherapy applications [5]. This study will highlight our most recent achievements in validating B7H6 as a lead protein biologic in cancer immunotherapy.

\section{Results and Discussion}

Flow cytometry was used to investigate the binding interactions of the soluble free form of B7H6 with the NK92-MI cells known to overexpress the cell surface NKp30 receptor. In a direct binding assay, Alexa Fluor 488-labeled B7H6 demonstrated similar binding to NK92-MI cells' (85\%) compared to the human APC-labeled antiNKp30 monoclonal antibody (95\%) (Figure 1). These initial results confirmed the NK cells' binding affinity of the B7H6 ligand. A competitive binding assay was next conducted in order to determine the NKp30 receptor binding specificities of the B7H6 ligand. In this assay, the NK92-MI cells were incubated with the Alexa Fluor 488-labeled B7H6 ligand, followed by treatment with the APC-labeled antiNKp30 monoclonal antibody. Flow cytometry analyses demonstrated partial displacement of B7H6 ( 70\%) upon addition of the antiNKp30 monoclonal antibody (Figure 2). Interestingly, when the NK92-MI cells were first incubated with the APC-labeled antiNKp30 monoclonal antibody, followed by treatment with the Alexa Fluor 488-labeled B7H6 ligand, no displacement was observed, suggesting allosteric binding of both ligands to the NKp30 receptor. Nevertheless, the ability for B7H6 to induce inflammatory responses on the NK92-MI cells was next evaluated by ELISA. In this assay, the NK92-MI cells were left untreated (negative control), and incubated with the soluble free form of B7H6 (test sample). Following a $24 \mathrm{~h}$ incubation period, the cells were harvested and media was tested for the secretion of the pro-inflammatory cytokines TNF $\alpha$ and IFN $\gamma$. In this assay, B7H6 was found to activate NK92-MI cells resulting in the release of pro-inflammatory cytokines $\mathrm{TNF} \alpha$ and IFN $\gamma$ (Figure 3). These results supports B7H6 as an immunostimulatory ligand of the NK92-MI cells for the development of cancer-targeted immunotherapy approaches. Moreover, B7H6 will be studied as a synergistic activator of proinflammatory cytokines as well as a trigger of potent immunological activities within diverse tumor microenvironments. 


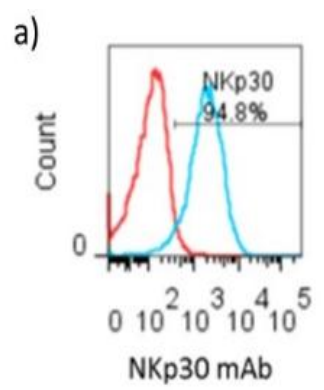

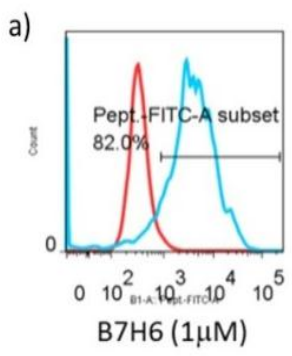

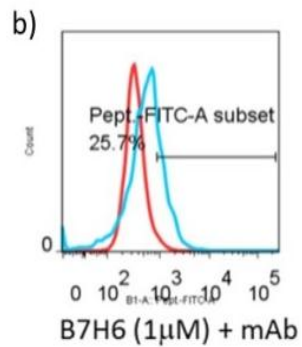

Fig. 1. Direct binding studies: Flow cytometry analyses of A. Anti-NKp3O APC labeled monoclonal antibody $(2 \mu L)$ and B. Alexa Fluor 488 labeled B7H6 ligand (1 mM, $20 \mu \mathrm{L}$ in PBS) with NK92-MI cells.

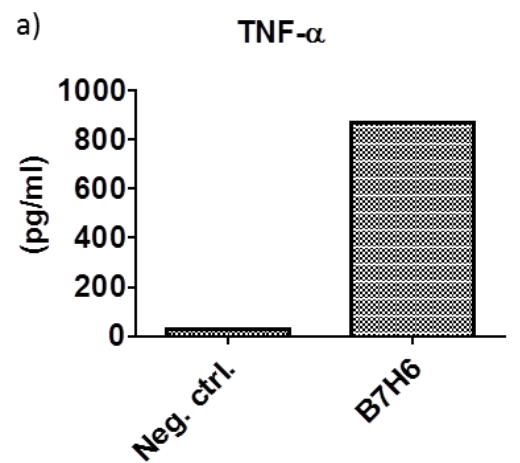

Fig. 2. Competitive binding studies: Flow cytometry analyses of A. Alexa Fluor 488 labeled B7H6 ligand (1 mM, $20 \mu \mathrm{L}$ in PBS) and B. Anti-NKp30 APC labeled monoclonal antibody $(2 \mu L)$ in the presence of Alexa Fluor 488 labeled B7H6 ligand (1 mM, $20 \mu \mathrm{L}$ in PBS) with NK92-MI cells.

b) IFN- $\gamma$

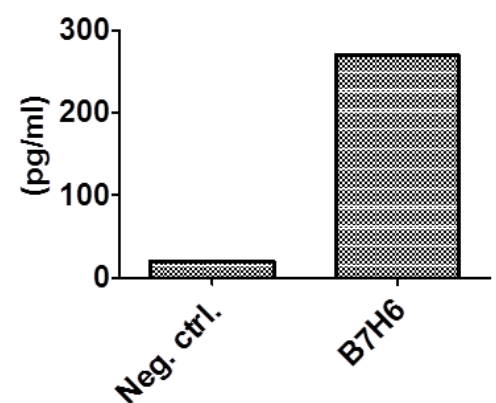

Fig. 3. Immunostimulatory Activity: ELISA of the NK92-MI cell excretion of A. TNF $\alpha$ and B. IFN- $\gamma$ in the presence of $B 7 H 6$ ligand $(0.5 \mathrm{mM}, 100 \mu \mathrm{L})$.

\section{Acknowledgments}

The authors would like to thank the Department of Chemistry and Biochemistry at Seton Hall University for continued support. The authors are also grateful to the $24^{\text {th }}$ APS for accommodating our research presentation.

\section{References}

1. Vivier, E., Tomaselo, E., Baratin, M., Walzer, T., Ugolini, S. Nat. Immunol. 9, 503-510 (2008), http://dx.doi.org/10.1038/ni1582

2. Pende, D., Parolini, S., Pessino, A., Sivori, S., Augugliaro, R., Morelli, L., Marcenaro, E., Accame, L., Malaspina, A., Biassoni, R., Bottino, C., Moretta, L., Moretta, A. J. Exp. Med. 190, 1505-1516 (1999), http://www.ncbi.nlm.nih.gov/pmc/articles/PMC2195691/

3. Li, Y., Wang, Q., Mariuzza, A. J. Exp. Med. 208, 703-714 (2011), http://dx.doi.org/10.1084/jem.20102548

4. Kaifu, T., Escaliere, B., Gastinel, L.N., Vivier, E., Baratin, M. Cell. Mol. Life Sci. 68, 3531-3539 (2011), http://dx.doi.org/10.1007/s00018-011-0802-7

5. Brandt, C.S., Baratin, M., Yi, E.C., Kennedy, J., Gao, Z., Fox, B., Haldeman, B., Ostrander, C.D., Kaifu, T., Chabannon, C., Moretta, A., West, R., Xu, W.F., Vivier, E., Levin, S.D. J. Exp. Med. 206, 1495-1503 (2009), http://dx.doi.org/10.1084/jem.20090681 